Article

\title{
Sustainable Decision Making Using a Consensus Model for Consistent Hesitant Fuzzy Preference Relations-Water Allocation Management Case Study
}

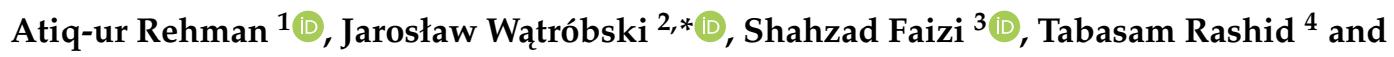 \\ Małgorzata Tarczyńska-Łuniewska 5 (D) \\ 1 Department of Mathematics, COMSATS University Islamabad at Lahore, Lahore 5400, Pakistan; \\ atiqurehman@cuilahore.edu.pk \\ 2 Institute of Management, University of Szczecin, Cukrowa 6, 71-104 Szczecin, Poland \\ 3 Department of Mathematics, Virtual University of Pakistan, Lahore 54000, Pakistan; shahzadfaizi@vu.edu.pk \\ 4 Department of Mathematics, University of Management and Technology, Lahore 54770, Pakistan; \\ tabasam.rashid@umt.edu.pk \\ 5 Institute of Economic and Finance, University of Szczecin, Mickiewicza 64, 71-101 Szczecin, Poland; \\ malgorzata.tarczynska@usz.edu.pl \\ * Correspondence: jaroslaw.watrobski@usz.edu.pl; Tel.: +48-91-444-1996
}

Received: 21 October 2020; Accepted: 24 November 2020; Published: 26 November 2020

\begin{abstract}
This paper presents an improved consensus-based procedure to handle multi-person decision making (MPDM) using hesitant fuzzy preference relations (HFPRs) which are not in normal format. At the first level, we proposed a Łukasiewicz transitivity ( $T_{L}$-transitivity) based scheme to get normalized hesitant fuzzy preference relations (NHFPRs), subject to which, a consensus-based model is established. Then, a transitive closure formula is defined to construct $T_{L}$-consistent HFPRs and creates symmetrical matrices. Following this, consistency analysis is made to estimate the consistency degrees of the information provided by the decision-makers (DMs), and consequently, to assign the consistency weights to them. The final priority weights vector of DMs is calculated after the combination of consistency weights and predefined priority weights (if any). The consensus process concludes whether the aggregation of data and selection of the best alternative should be originated or not. The enhancement mechanism is indulged in improving the consensus measure among the DMs, after introducing an identifier used to locate the weak positions, in case of the poor consensus reached. In the end, a comparative example reflects the applicability and the efficiency of proposed scheme. The results show that the proposed method can offer useful comprehension into the MPDM process.
\end{abstract}

Keywords: consistency weights; fuzzy preference relation (FPR); hesitant fuzzy preference relation (HFPR); Łukasiewicz consistency; normal hesitant fuzzy preference relation (NHFPR)

\section{Introduction}

Making decisions is an integral part of human life. Many of them require "rational" or "good" decisions to be sought from decision makers (DMs), taking into account different criteria for evaluating individual decision options [1,2]. A typical practical area where the choice of a decision option requires consideration of a set of conflicting criteria is the domain of sustainability [3,4]. In such situations, the evaluation of decision alternatives with consideration of ecological, economic and social perspectives is carried out using multi-criteria decision support methods $[5,6]$.

In modern society, multi-person decision making (MPDM) is an important process of getting optimal decision results [7]. In any case, the evaluation contributed by DMs might well fluctuate depending on different interpretation skills, experience and judgments of the DMs [8,9]. Therefore, 
it is difficult to achieve a unified consensus under this condition [10]. This is a significant issue for the assessment of the outcomes of decisions that are generally appropriate to most DMs when the decision-making process originates. However, a great challenge for the researchers is to achieve unanimous and acceptable decision results and approach a strong consensus level [11]. Therefore, different algorithms to reach a strong consensus level in a GDM process have been thoroughly studied. For instance, Zhang et al. [12] established a maximum support degree consensus model under hesitant information and linguistic assessments. Li et al. [13] introduced an interactive process of reaching the consensus level at uncertain and minimum cost. $\mathrm{Li}$ and Wang [14] proposed an automatic iterative algorithm to reach a consensus level in the context of probabilistic hesitant fuzzy preference relations. Tian and Wang et al. [15] established signed distance-based consensus measures on three levels with multi-granular hesitant unbalanced linguistic assessments to find the consensus degree. Zhang et al. [16] developed a consensus model with heterogeneous large-scale GDM with satisfaction and individual concerns. Furthermore, Herrera-Viedma et al. [17] studied analysis of consensus-reaching models in fuzzy environments.

In MPDM processes, the consensus-building mechanism is commonly used as a tool based on preference relations. The definition of hesitant fuzzy preference relation (HFPR) developed by Xia and $\mathrm{Xu}$ [18], which is now being used as an efficient and easy method for communicating alternative data for a group of DMs, e.g., while providing the decision degree to which an alternative $x_{1}$ is preferable to another alternative $x_{2}$ for a group of three DMs. Suppose three DMs provide $0.3,0.4$ and 0.5 , respectively. If all the DMs cannot establish a consensus to accept their assessment, then a set comprising their combined decisions in the form of the hesitant fuzzy element (HFE) $\{0.3,0.4,0.5\}$ can be considered as the preference degree of $x_{1}$ to $x_{2}$. The HFPR proposed in [18] has been studied by many researchers in the perspective of GDM [19-21] but despite all these extensive studies and developments, certain disputes remain. The immediate benefit of the HFPR is that the DMs may have a set of values that display the consequences of the assessment. However, the HFEs in the HFPR will provide a specific number of elements that can cause difficulties in creating a consensus in the decision-making process. For instance, most consensus models are focused on distance calculation between two HFPRs, and it is very difficult to determine an effective distance between two unequal HFEs [22]. As a result, DMs are confused in deriving the priority weight vectors from the HFPR having unequal HFEs [23]. Based on this discussion, it raises a query that either a normalization-based method is rational after reviewing all these controversies. However, some researchers focused on using the normalization-based method, and others denied this idea [24].

The normalization-based method required any two HFEs to have an equal number of elements. Various scholars in the decision-making process have greatly appreciated this method. In the case of those HFEs having an unequal number of elements, the HFEs having an equal number of elements can be obtained by inserting various elements to the shorter one or removing several elements in the longer HFE. Zhu et al. [23] initially introduced $\alpha$ and $\beta$ normalization methods. Based on these two methods, many researchers have developed different methods of the extraction of priority weight vector as well as the consensus reaching models [25,26]. Zhang and $\mathrm{Wu}[26]$ designed goal programming models for incomplete hesitant multiplicative preference relation and determine the priority weight vectors by using $\alpha$ and $\beta$ normalization methods. Meng et al. [27] proposed a new consistency concept for hesitant multiplicative preference relations and then derive the hesitant fuzzy priority weight vector. Furthermore, Zhang [28] developed a goal-programming model for an incomplete HFPR and derive priority weight vectors based on $\alpha$ and $\beta$ normalization methods respectively. Zhang et al. and $\mathrm{Li}$ et al. [29,30] defined some preference relations based on $q$-rung orthopair fuzzy sets and investigated a technique to obtain the priority weights from individual or group $q$-rung orthopair fuzzy preference relations. Since various scholars have continuously forced on using these two methods, therefore, various new normalization methods have been constructed, for example, $\mathrm{Xu}$ et al. [31] introduced an additive consistency-based normalization method and developed a consensus model for solving water allocation management problems. 
Due to the limited expertise and experience of DMs, it can be difficult for them to establish complete preference relations during pairwise decisions on alternatives $[32,33]$. Therefore, there is a need for the development of some approaches which help to manage HFPRs with incomplete information. Based on the additive consistency of HFPR, Zhang et al. [34] proposed a method to guess missing elements of an incomplete HFPR. Zhang [28] further defined the multiplicative consistency of an HFPR, and by using a normalization method, the missing elements of HFPR were estimated based on the multiplicative consistency. Based on the additive consistency and multiplicative consistency of incomplete HFPRs in local and group decision-making settings, $\mathrm{Xu}$ et al. [21] designed mixed 0-1 programming models to find a priority weight vector from incomplete HFPRs. To estimate the missing elements for an incomplete HFPR, Khalid and Beg [35] proposed an algorithm by utilizing hesitant upper bound condition for the DMs.

The stability of preference relations plays a critical role in the decision-making phase in the pairwise assessments of DM's preferences [36]. The idea of the consistency of fuzzy preference relation was extended to establish the concept of consistency of HFPR. It is very important to measure the consistency of fuzzy preference relations to get consistent results from a decision making process. By using the $\alpha$-normalization method, Zhu [37] introduced a regression method and established a methodology to transform HFPR into a fuzzy preference relation having the highest level of consistency measure. To measure the consistency level of HFPR, the distance measure between normalized HFPR and consistent HFPR plays an important role. By using this idea, Zhang et al. [38] constructed a consistent HFPR based on the concept of additive consistency and multiplicative consistency of HFPR. Some feedback and automatic optimization algorithms were developed in the same study to improve the consistency level of those HFPRs which are not of acceptable consistency [39]. Liu et al. [40] derived some operational laws for fuzzy preference relations with self-confidence. They presented an additive consistency index that reflects both the fuzzy preference values and self-confidence to include their consistency levels.

A concise literature review shows that the consensus reaching process must be considered in MPDM problems. As discussed in our previous works, while outstanding achievements in this field have been made, very little work has been centered on consensus and consistency measures and, therefore, the novelty of our paper is to establish a consensus model in the context of HFPRs, based on another effective consistency measure approach called the $T_{L}$-consistency. This research study is based on two research questions. The first one is to propose a consensus-based method to handle MPDM problem using consistent HFPRs, and the second one is to incorporate an enhancement mechanism to accelerate the execution of a higher consensus level on an easy path. In this paper, the authors present an improved technique for consensus proposing in group decision making based on $T_{L}$-consistency in HFPRs environment. As consistency is an important issue to accept when the experts provide data, the proposed method can estimate more reasonable and consistent values when an FPR carries missing preferences. Consistency is associated with the transitivity property for which several useful forms or conditions have been suggested in the literature of FPRs [41]. The weakest of them is $T_{L}$-transitivity, i.e., $r_{i k} \geq \max \left(r_{i j}+r_{j k}-1,0\right)$, and it is the most appropriate notion of transitivity for fuzzy ordering [42]. Therefore, the individual and collective FPRs obtained by this method are fully consistent under the use of t-norm. At the first step, we evaluate the missing preferences of IFPRs using $T_{L}$-transitivity property. Then, we propose the changed consistency matrices of experts, which have to satisfy the $T_{L}$-consistency, and measure the level of consistency. The degree of significance is given to the experts based on accuracy weights aggregated with confidence weights. The proposed approach provides us with a powerful way to create consensus in group decision-making based on $T_{L}$-transitivity with IFPRs.

This manuscript is organized as follows: in Section 2, some basic definitions are provided to facilitate the paper understanding. In Section 3, a new procedure to normalize the HFPRs is proposed and further extended to the MPDM problem using consistency and consensus measures, respectively. Section 4 is comprised of a comparative example to examine the efficiency of the proposed method. 
Section 5 provides a comparison of the results obtained, using our proposed technique, with the ones in the literature. The last section includes some conclusions.

\section{Preliminaries}

In this section, some basic information is given in order to better understand the article. L. A. Zadeh introduced the notion of a fuzzy set [43] in 1965 and used it to illustrate how an entity is more or less connected to a particular category that we want to conform to.

Definition 1. Fuzzy Set [43]: A set $A$ on universe $X$ associated with a mapping from $X$ to $[0,1]$ is called fuzzy set, symbolizes as $A=\{(x, A(x))\}$. The output $A(x)$ for all $x \in X$ is known as the degree to which $x$ belongs to $A$ i.e., $A(x)=\operatorname{Degree}(x \in A)$ under the membership function $A: X \rightarrow[0,1]$.

Definition 2. Hesitant Fuzzy Set [44]: A hesitant fuzzy set A on a fixed finite set $X$ is associated with a function $h_{A}(x)$ from $X$ to a finite subset of $[0,1]$.

To have been properly described, Xia and Xu [45] articulate the HFS with following mathematical symbol:

$$
E=\left\{<x, h_{E}(x)>\mid x \in X\right\},
$$

where $h_{E}(x)$ is a set of some values in $[0,1]$, denoting the possible membership degrees of the element $x \in X$ to the set $E$. For convenience, Xia and Xu [45] named $h_{E}(x)$ a hesitant fuzzy element (HFE).

Definition 3. Fuzzy Preference Relation [46]: A relation $R$ on a finite set $X=\left\{x_{1}, x_{2}, x_{3}, \ldots, x_{n}\right\}$ of alternatives characterized by law $R: X \times X \rightarrow[0,1]$, satisfying: $r_{i j}+r_{j i}=1$ (additive reciprocity) for $1 \leq i \leq n$ and $1 \leq j \leq n$, is called a fuzzy preference relation where $r_{i j}$ denotes the degree of preference of alternative $x_{i}$ to the alternative $x_{j}$ with $R\left(x_{i}, x_{j}\right)=r_{i j} \in[0,1]$. If $r_{i j}=0.5$, then there is no difference between the alternatives $x_{i}$ and $x_{j}$. If $r_{i j}>0.5$, then alternative $x_{i}$ is preferred over the alternative $x_{j}$, if $r_{i j}=1$, then the alternative $x_{i}$ is definitely preferred over the alternative $x_{j}$.

Definition 4. Hesitant Fuzzy Preference Relation [31]: Let $X=\left\{x_{1}, x_{2}, \ldots, x_{n}\right\}$ be a fixed set, and then the HFPR on $X$ is expressed by a matrix $H=\left(h_{i j}\right)_{n \times n} \subset X \times X$, where $h_{i j}=\left\{h_{i j}^{\beta} \mid \beta=1,2, \ldots, \# h_{i j}\right\}$ is hesitant fuzzy preference value (HFPV) that indicates all the possible preference degrees of alternative $x_{i}$ over $x_{j}$. Moreover, $h_{i j}$ must satisfy the following conditions:

$$
\left\{\begin{array}{l}
h_{i j}^{\beta}+h_{j i}^{\beta}=1, i, j=1,2, \ldots, n \\
h_{i i}=\{0.5\}, i=1,2, \ldots, n \\
\# h_{i j}=\# h_{j i}, i, j=1,2, \ldots, n
\end{array},\right.
$$

where $\# h_{i j}$ is the number of values in $h_{i j}$, and $h_{i j}^{\beta}$ is the $\beta$ th element in $h_{i j}$.

Definition 5. Incomplete Fuzzy Preference Relation [47]: A FPR $R=\left(r_{i j}\right) n \times n$ is considered to be incomplete if it includes at least one uncertain value of preference $r_{i j}$ for which the expert has no idea of the degree of preference of alternative $x_{i}$ over $x_{j}$.

Definition 6. Consistent Fuzzy Preference Relation: A FPR $R$ is said to be $T_{L}$-consistent, if for $i, k \neq j \in$ $\{1,2,3, \ldots, n\}: r_{i k} \geq \max \left(r_{i j}+r_{j k}-1,0\right)\left(T_{L}\right.$-transitivity $)$ is satisfied.

\section{Proposed Procedure}

In this section, the authors presented an improved procedure to handle MPDM problems using HFPRs, and comprising of: normalization process; consistency measures; consensus measures; consensus improving process; assigning priority weights to decision makers and selection process (aggregation and ranking process). 


\subsection{Normalization Process}

In this subsection, a new procedure to normalize HFPRs is proposed, because in most of the cases for any two hesitant fuzzy preference values (HFPVs) $h_{i j}$ and $h_{l m},\left|h_{i j}\right| \neq\left|h_{l m}\right|$ for $i, j, l, m \in\{1,2,3, \ldots, n\}$ where $\left|h_{i j}\right|$ and $\left|h_{l m}\right|$ represent the cardinalities of sets of pairwise comparisons at $i j$ th and $l m$ th positions. In order to operate smoothly, Zhu et al. [23] presented a procedure known as $\beta$-normalization to construct HFPRs with preference values having same cardinalities. This study includes that if $h_{i j}=\left\{h_{i j}^{\beta}|\beta=1,2, \ldots,| h_{i j} \mid\right\}$ is a HFPV with $h_{i j}^{+}$and $h_{i j}^{-}$as maximum and minimum elements in $h_{i j}$, respectively, and let $\xi(0 \leq \xi \leq 1)$ be a parameter, then the element $\bar{h}_{i j}$ to be added can be estimated using $\bar{h}_{i j}=\xi h_{i j}^{+}+(1-\xi) h_{i j}^{-}$. In particular sense, $\xi=1$ implies that $\bar{h}_{i j}=h_{i j}^{+}$, and $\bar{h}_{i j}=h_{i j}^{-}$when $\xi=0$, which are known as optimism and pessimism rules in Xu and Xia [48]'s approach, respectively.

There are some restrictions that exist in both the techniques described above. In Zhu et al. [23]'s technique, various possibilities exist to normalize the HFPVs, it is due to the different values of parameter $\xi$. In $\mathrm{Xu}$ and Xia [48]'s approach, the estimated element is only the maximum or minimum entry of HFPV and other intermediate values cannot be taken as an added element. Due to these restrictions, $\mathrm{Xu}$ et al. [31] presented another scheme to normalize the given HFPRs based on additive transitivity.

After getting motivation from Xu et al. [31]'s work, we put forward a new scheme to estimate the elements to be added in HFPVs regarding the normalization of the given HFPRs. The proposed scheme is based on $T_{L}$-consistency in which we take the elements to be added as unknown preference values, and construct the incomplete fuzzy preference relation(s) (IFPR(s)). It is to be noted that an IFPR can only be completed based on the $T_{L}$-consistency if each one of the alternatives is compared at least once among the known preference values. Thus, the system needs to ask the expert to form an adequate number of preferences in which each one of the alternatives is compared at least once to let the IFPR become a complete FPR. The order of measuring the missing preference values affects the final result. In order to determine the unknown preference values in an IFPR $R=\left(r_{i j}\right)_{n \times n}$, the following sets can be defined to represent the pairs of alternatives for known and unknown preference values:

$$
\begin{aligned}
& K_{e}=\left\{(i, j) \mid r_{i j} \text { is known }\right\}, \\
& U_{e}=\left\{(i, j) \mid r_{i j} \text { is unknown }\right\},
\end{aligned}
$$

where $r_{i j} \in[0,1]$ shows the preference values of alternative $a_{i}$ over the alternative $a_{j}, r_{i j}+r_{j i}=$ $1 \Longrightarrow r_{i i}=0.5 \forall i \in\{1,2, \ldots, n\}$. Therefore, the following set can be defined to estimate the unknown preference value $r_{i j}$ of alternative $a_{i}$ over alternative $a_{j}$ based on $T_{L}$-transitivity $r_{i k} \geq$ $\max \left(r_{i k}+r_{k j}-1,0\right)$ :

$$
E_{i j}=\left\{k \neq i, j \mid(i, k) \in K_{e},(k, j) \in K_{e} \text { and }(i, j) \in U_{e}\right\},
$$

for $i, j, k \in\{1,2,3, \ldots, n\}$. Based on Equation (3), final value of $r_{i j}$ is estimated using:

$$
r_{i j}=\left\{\begin{array}{ll}
\underset{k \in E_{i j}}{\operatorname{ave}\left(\max \left(r_{i k}+r_{k j}-1,0\right)\right),} & \text { if }\left|E_{i j}\right| \neq 0 \\
0.5, & \text { otherwise }
\end{array} .\right.
$$

To get satisfy the additive reciprocity $\left(r_{i j}+r_{j i}=1\right)$ of constructed complete preference relation $R$ in case of $r_{i j}+r_{j i}>1$ or $r_{i j}+r_{j i}<1$, following scaling condition helps us:

$$
\left(r_{i j}-g\right)+\left(r_{j i}-g\right)=1 \text { such that } g=\frac{r_{i j}+r_{j i}-1}{2} .
$$


Finally, a complete FPR $R^{*}=\left(r_{i j}^{*}\right)_{n \times n}$ is obtained, where $r_{i j}^{*}=r_{i j}-g$ such that $r_{i j}^{*}+r_{j i}^{*}=1$. Now, two new sets $K_{e}^{\prime}$ and $U_{e}^{\prime}$ of known and unknown elements are defined as follows:

$$
K_{e}^{\prime}=K_{e} \cup\{(i, j)\} \text {, and } U_{e}^{\prime}=U_{e}-\{(i, j)\} .
$$

Consequently, a normalized hesitant fuzzy preference relation (NHFPR) $H^{*}=\left(h_{i j}^{*}\right)_{n \times n}$ with $h_{i j}^{* \beta}+h_{j i}^{* \beta}=1, h_{i j}^{*}=\left\{h_{i j}^{* \beta}|\beta=1,2, \ldots,| h_{i j}^{*} \mid\right\}$ for $\left|h_{i j}^{*}\right|=\left|h_{j i}^{*}\right|$, is constructed. In real world, there are many decision-making processes which take place in multi-person settings because the increase of complexity and uncertainty of the socio-economic environment makes it less possible for a single decision maker to consider all related traits of a decision-making problem.

Example 1. Let $H$ be the following HFPR:

$$
H=\left[\begin{array}{rlrl}
\{0.5\} & \{0.3\} & \{0.5,0.7\} & \{0.4\} \\
\{0.7\} & \{0.5\} & \{0.7,0.9\} & \{0.8\} \\
\{0.5,0.3\} & \{0.3,0.1\} & \{0.5\} & \{0.6,0.7\} \\
\{0.6\} & \{0.2\} & \{0.4,0.3\} & \{0.5\}
\end{array}\right] .
$$

To normalize $H$, first, we have to transform it into two FPRs as follows:

$$
R_{1}=\left[\begin{array}{llll}
0.5 & 0.3 & 0.5 & 0.4 \\
0.7 & 0.5 & 0.7 & 0.8 \\
0.5 & 0.3 & 0.5 & 0.6 \\
0.6 & 0.2 & 0.4 & 0.5
\end{array}\right], R_{2}=\left[\begin{array}{llll}
0.5 & r_{12} & 0.7 & r_{14} \\
r_{21} & 0.5 & 0.9 & r_{24} \\
0.3 & 0.1 & 0.5 & 0.7 \\
r_{41} & r_{42} & 0.3 & 0.5
\end{array}\right]
$$

Clearly, $R_{2}$ is an IFPR. Now, we estimate the unknown preference values using $T_{L}$-consistency based procedure as follows:

(Round-i) The sets of pairs of alternatives for known and unknown preference values, respectively, are:

$$
\begin{aligned}
& K_{e}=\{(1,3),(2,3),(3,1),(3,2),(3,4),(4,3)\}, \\
& U_{e}=\{(1,2),(1,4),(2,1),(2,4),(4,1),(4,2)\} .
\end{aligned}
$$

Here, we neglect the diagonal entries. To find the value of $r_{12}$, the set $E_{12}$ of intermediate alternatives $a_{k}$ is defined such that $(1, k),(k, 2) \in K_{e}$, as:

$$
E_{12}=\{3\}
$$

Now, the value of $r_{12}$ is estimated based on $E_{12}$ as:

$$
r_{12}=\max \left(r_{13}+r_{32}-1,0\right)=\max (0.7+0.1-1,0)=0 .
$$

The new sets of known and unknown preference values are:

$$
\begin{gathered}
K_{e}^{\prime}=\{(1,2),(1,3),(2,3),(3,1),(3,2),(3,4),(4,3)\}, \\
U_{e}^{\prime}=\{(1,4),(2,1),(2,4),(4,1),(4,2)\} .
\end{gathered}
$$


After repeating the process as in Round-i, we can easily estimate the remaining values $r_{14}, r_{21}, r_{24}, r_{41}$ and $r_{42}$. After evaluating all the missing values, we get:

$$
R_{2}=\left[\begin{array}{cccc}
0.5 & 0 & 0.7 & 0.4 \\
0.2 & 0.5 & 0.9 & 0.3 \\
0.3 & 0.1 & 0.5 & 0.7 \\
0 & 0 & 0.3 & 0.5
\end{array}\right]
$$

The scaling condition (5) helps us to construct the following FPR $R_{2}$ after getting the complete form:

$$
R_{2}=\left[\begin{array}{cccc}
0.5 & 0.4 & 0.7 & 0.7 \\
0.6 & 0.5 & 0.9 & 0.65 \\
0.3 & 0.1 & 0.5 & 0.7 \\
0.3 & 0.35 & 0.3 & 0.5
\end{array}\right]
$$

Hence, the NHFPR $H^{*}$ is constructed as:

$$
H=\left[\begin{array}{cccc}
\{0.5,0.5\} & \{0.3,0.4\} & \{0.5,0.7\} & \{0.4,0.7\} \\
\{0.7,0.6\} & \{0.5,0.5\} & \{0.7,0.9\} & \{0.8,0.65\} \\
\{0.5,0.3\} & \{0.3,0.1\} & \{0.5,0.5\} & \{0.6,0.7\} \\
\{0.6,0.3\} & \{0.2,0.35\} & \{0.4,0.3\} & \{0.5,0.5\}
\end{array}\right]
$$

\subsection{Consistency Analysis}

In this subsection, some consistency measures, such as consistency level of pair of alternatives, consistency level of alternatives and the consistency level of HFPR, are defined. The term consistency index $(C I)$ stands for consistency degree whose value lies in $[0,1]$.

Let $H^{q}$ be the HFPR associated to the decision maker $D_{q}(1 \leq q \leq l)$, then after getting NHFPR $H^{* q}, T_{L}$-consistent HFPR $\widetilde{H^{* q}}$ can be obtained with the help of following transitive closure formula:

$$
\widetilde{h_{i j}^{* q \beta}}=\max _{k \neq i, j}\left(h_{i j}^{* q \beta}, \max \left(h_{i k}^{* q \beta}+h_{k j}^{* q \beta}-1,0\right)\right), \widetilde{h_{i j}^{* q \beta}}+\widetilde{h_{j i}^{* q \beta}}=1
$$

where $h_{i j}^{* q}=\left\{h_{i j}^{* q \beta}|\beta=1,2, \ldots,| h_{i j}^{q *} \mid\right\}$. Now, we can estimate the consistency level of HFPR $H^{* q}$ based on its similarity with the corresponding $T_{L}$-consistency $\widetilde{H^{* q}}$ after evaluating distance between them in the following manner.

1. $T_{L}$ consistency index $\left(T_{L} C I\right)$ for a pair of alternatives evaluated as:

$$
T_{L} C I\left(h_{i j}^{* q}\right)=1-\frac{1}{\left|h_{i j}^{*}\right|} \sum_{\beta=1}^{\left|h_{i j}^{*}\right|} d\left(h_{i j}^{* q \beta}, \widetilde{h_{i j}^{* q \beta}}\right)
$$

where $d\left(h_{i j}^{* q \beta}, \widetilde{h_{i j}^{* q \beta}}\right)$ represents the distance obtained by $d\left(h_{i j}^{* q \beta}, \widetilde{h_{i j}^{* q \beta}}\right)=\left|h_{i j}^{* q \beta}-\widetilde{h_{i j}^{* q \beta}}\right|$. Usually, the higher the level of $T_{L} C I\left(h_{i j}^{* q}\right)$, the more consistent $h_{i j}^{* q}$ is as compared to the rest of HFPVs regarding alternatives $a_{i}$ and $a_{j}$.

2. $T_{L} C I$ for alternatives $a_{i}, 1 \leq i \leq n$, is determined as:

$$
T_{L} C I\left(a_{i}\right)=\frac{1}{2(n-1)} \sum_{j=1, j \neq i}^{n}\left(T_{L} C I\left(h_{i j}^{* q}\right)+T_{L} C I\left(h_{j i}^{* q}\right)\right)
$$


with $T_{L} C I\left(a_{i}\right) \in[0,1]$. If $T_{L} C I\left(a_{i}\right)=1$, then the preference values concerning alternative $a_{i}$ are fully consistent, else the smaller $T_{L} C I\left(a_{i}\right)$ the more inconsistent these preference values are.

3. At the end, $T_{L} C I$ against NHFPR $H^{* q}$ is evaluated using average operator:

$$
T_{L} C I\left(H^{* q}\right)=\frac{1}{n} \sum_{i=1}^{n} T_{L} C I\left(a_{i}\right)
$$

with $T_{L} C I\left(H^{* q}\right) \in[0,1]$. If $T_{L} C I\left(H^{* q}\right)=1$, then NHFPR $H^{* q}$ is fully consistent, else the smaller $T_{L} C I\left(H^{* q}\right)$ the more inconsistent $H^{* q}$ is.

The consistency index evaluated by Equation (10) is associated with DM $D_{q}$, while the global consistency index $\mathrm{CI}$ can be measured using average operator and given as:

$$
C I=\frac{1}{l} \sum_{q=1}^{l} T_{L} C I\left(H^{* q}\right)
$$

with $C I \in[0,1]$. Once, the $T_{L} C I$ is measured in three stages involving Equations (8)-(10), it is expressible to assign higher weights to the experts which provided the HFPR with larger consistency indices respectively. Therefore, consistency weights can be allocated to the experts using following relation:

$$
C w(D q)=\frac{T_{L} C I\left(H^{* q}\right)}{\sum_{q=1}^{l} T_{L} C I\left(H^{* q}\right)}
$$

with $C w(D q) \in[0,1]$ and $\sum_{q=1}^{l} C w(D q)=1$.

\subsection{Consensus Analysis}

In this subsection, some levels to estimate global consensus degree amongst decision makers are defined. After evaluating NHFPRs $H^{* q}, q=1,2, \ldots, l$, it is essential to estimate the consensus level amongst the decision makers. In relation to this, a collective similarity matrix $S=\left(s_{i j}\right)_{n \times n}$ can be obtained, after aggregating the similarity matrices $S^{q r}=\left(s_{i j}^{q r}\right)_{n \times n}$ for every pair of decision makers $\left(D_{q}, D_{r}\right)(q=1,2, \ldots, l-1 ; r=q+1, \ldots, l)$, as follows:

$$
S=\left(s_{i j}\right)_{n \times n}=\left(\frac{2}{l(l-1)} \sum_{q=1}^{l-1} \sum_{r=q+1}^{l}\left(1-\frac{1}{\left|h_{i j}^{*}\right|} \sum_{\beta=1}^{\left|h_{i j}^{*}\right|} d\left(h_{i j}^{* q \beta}, h_{i j}^{* r \beta}\right)\right)\right)_{n \times n}
$$

where $1-\frac{1}{\left|h_{i j}^{*}\right|} \sum_{\beta=1}^{\left|h_{i j}^{*}\right|} d\left(h_{i j}^{* q \beta}, h_{i j}^{* r \beta}\right)=s_{i j}^{q r}$ and $d\left(h_{i j}^{* q \beta}, h_{i j}^{* r \beta}\right)=\left|h_{i j}^{* q \beta}-h_{i j}^{* r \beta}\right|, \beta=\left\{1,2, \ldots,\left|h_{i j}^{*}\right|\right\}$.

The following levels involve to estimate the global consensus degree amongst the decision makers:

1. At the first level, the consensus degree on a pair of alternatives $\left(a_{i}, a_{j}\right)$, denoted by $c d_{i j}$ is defined to estimate the degree of consensus amongst all experts on that pair of alternatives:

$$
c d_{i j}=s_{i j}
$$


2. At the second level, the consensus degree on alternatives $a_{i}$ denoted by $C D_{i}$, is defined to determine the consensus degree amongst all the experts on that alternative:

$$
C D_{i}=\frac{1}{2(n-1)} \sum_{j=1, j \neq i}^{n}\left(s_{i j}+s_{j i}\right)
$$

3. At the third level, the consensus degree on the relation denoted by $C R$, is defined to calculate the global degree of consensus amongst all DMs:

$$
C R=\frac{1}{n} \sum_{i=1}^{n} C D_{i}
$$

If the global consensus level of all experts is reached, it needs a comparison with the threshold consensus degree $\eta$, usually pre-determined based on the nature of the issue. If $C R \geq \eta$ is obtained, this indicates that a sufficient degree of consensus has been achieved and the decision-making process starts. Otherwise, the consensus degree is not stable, and experts are asked to revise their preferences.

\subsection{Enhancement Mechanism}

The enhancement mechanism plays the role of a moderator in the consensus-reaching process and provides comprehensive information to decision makers in order to enhance their findings. In case of insufficient consensus level, we have to identify the positions at which preference values are to be modified, so as to reach the acceptable consensus degree amongst the decision makers. In this regard, an identifier is defined as follow:

$$
I^{q}=\left\{(i, j) \mid c d_{i j}<C R \text { and } h_{i j}^{q \beta} \text { is a known value }\right\}
$$

As soon as an identifier has determined the positions, the enhancement mechanism suggests the respective DM $D_{q}$ to increase the element $h_{i j}^{q \beta}$ of HFPV $h_{i j}^{q}$, if it is smaller than the mean value $h_{i j \text {, ave }}^{* q \beta}$ of the opinions by the participants, or to decrease in case of higher than the mean, and remains the same in case of equal to mean.

The advice made above only provides the direction to DMs for updating their preferences, but is unable to suggest the values. In order to update the element(s) of HFPV, the DMs are suggested to choose the new element $h_{i j \text {, new }}^{q \beta}$ from the interval $\left[\min \left(h_{i j}^{q \beta}, h_{i j, \text { ave }}^{* q \beta}\right), \max \left(h_{i j}^{q \beta}, h_{i j, \text { ave }}^{* q \beta}\right)\right]$.

In order to enhance the consensus automatically, the DMs would not have to provide their updated elements in automatic mechanism. In such a situation, the following expression could be used to evaluate the new element $h_{i j, \text { new }}^{q \beta}$ for $c d_{i j}<C R$ :

$$
h_{i j, \text { new }}^{q \beta}=\lambda h_{i j}^{q \beta}+(1-\lambda) h_{i j, \text { ave }}^{* q \beta}
$$

where $\lambda \in[0,1]$ is known as the optimization parameter. It is obvious that the new evaluated values will be closer to mean values as compare to old ones, and hence the consensus degree enhances.

\subsection{Rating of Decision Makers}

The final priority rating of decision makers is evaluated by emerging consistency weights and predefined priority weights as:

$$
w\left(D_{q}\right)=\frac{\omega_{q} \times C w(D q)}{\sum_{q=1}^{l} \omega_{q} \times C w(D q)}
$$


where $\omega_{q}, 1 \leq q \leq l$, represent the predefined priority weights of decision makers, while $\sum_{q=1}^{l} w\left(D_{q}\right)=1$. If the decision makers do not carry a predefined priority weights, then their consistency weights will be considered as the final priority rating.

\subsection{Aggregated NHFPR}

It may habitually occurs that the preference level associated to each DM is weighted differently. After evaluating the priority rating of decision makers, their opinions are to be aggregated into global one. We construct the collective consistent NHFPR $H^{* c}$ using weighted average operator as:

$$
H^{* c}=\left(h_{i j}^{* c}\right)_{n \times n}=\left(\sum_{q=1}^{l} w\left(D_{q}\right) \times \widetilde{h_{i j}^{* q}}\right)_{n \times n}
$$

for $1 \leq i \leq n, 1 \leq j \leq n$.

\subsection{Ranking of Alternatives}

As soon as the consensus amongst the decision makers is reached at an acceptable level, the process to rank the alternatives initiates and chooses the best one. In this regard, we define the ranking value $v\left(a_{i}\right)$ of alternative $a_{i}, i=1,2, \ldots n$, as follows:

$$
v\left(a_{i}\right)=\frac{2}{n(n-1)} \sum_{\substack{j=1 \\ j \neq i}}^{n}\left(\frac{1}{\left|h_{i j}^{* c}\right|} \sum_{\beta=1}^{\mid h_{i j}^{* c \mid}} h_{i j}^{* c \beta}\right)
$$

with $\sum_{i=1}^{n} v\left(a_{i}\right)=1$.

\section{Comparative Example}

In this section, we apply the proposed consensus-based procedure on a case study attempted by $\mathrm{Xu}$ et al. [31] to allocate water in the Jiangxi Province, China.

The following four alternatives with specific traits are considered as water allocation alternatives: (i) The first alternative $a_{1}$ is associated to social factor. (ii) The economic factor is considered by second alternative $a_{2}$. (iii) The third alternative $a_{3}$ considers the ecological factors to protect the local ecological environment. (iv) The final alternative $a_{4}$ thinks of the final output and return the local important scare resources.

A team of four decision makers $D_{q}, q=1,2,3,4$, from different departments is organized to provide assessments on the four alternatives $a_{i}, i=1,2,3,4$. After pairwise comparisons, following HFPRs $H^{q}, q=1,2,3,4$, are provided by the decision makers $D_{q}, q=1,2,3,4$, respectively.

$$
\begin{gathered}
H^{1}=\left[\begin{array}{rcrl}
\{0.5\} & \{0.3\} & \{0.5,0.7\} & \{0.4\} \\
\{0.7\} & \{0.5\} & \{0.7,0.9\} & \{0.8\} \\
\{0.5,0.3\} & \{0.3,0.1\} & \{0.5\} & \{0.6,0.7\} \\
\{0.6\} & \{0.2\} & \{0.4,0.3\} & \{0.5\}
\end{array}\right], \\
H^{2}=\left[\begin{array}{cccc}
\{0.5\} & \{0.3,0.5\} & \{0.1,0.2\} & \{0.6\} \\
\{0.7,0.5\} & \{0.5\} & \{0.7,0.8\} & \{0.1,0.3,0.5\} \\
\{0.9,0.8\} & \{0.3,0.2\} & \{0.5\} & \{0.5,0.6,0.7\} \\
\{0.4\} & \{0.9,0.7,0.5\} & \{0.5,0.4,0.3\} & \{0.5\}
\end{array}\right],
\end{gathered}
$$




$$
\begin{array}{r}
H^{3}=\left[\begin{array}{cccc}
\{0.5\} & \{0.3,0.5\} & \{0.7\} & \{0.7,0.8\} \\
\{0.7,0.5\} & \{0.5\} & \{0.2,0.3,0.4\} & \{0.5,0.6\} \\
\{0.3\} & \{0.8,0.7,0.6\} & \{0.5\} & \{0.7,0.8,0.9\} \\
\{0.3,0.2\} & \{0.5,0.4\} & \{0.3,0.2,0.1\} & \{0.5\}
\end{array}\right] \\
H^{4}=\left[\begin{array}{cccc}
\{0.5\} & \{0.4,0.5,0.6\} & \{0.3,0.4\} & \{0.5,0.7\} \\
\{0.6,0.5,0.4\} & \{0.5\} & \{0.3\} & \{0.6,0.7,0.8\} \\
\{0.7,0.6\} & \{0.7\} & \{0.5\} & \{0.8,0.9\} \\
\{0.5,0.3\} & \{0.4,0.3,0.2\} & \{0.2,0.1\} & \{0.5\}
\end{array}\right]
\end{array}
$$

Normalization:

In order to normalize the given information, expressions (1)-(6) were used to construct NHFPRs as (22)-(25).

$$
\begin{aligned}
& H^{* 1}=\left[\begin{array}{cccc}
\{0.5,0.5,0.5\} & \{0.3,0.4,0.3\} & \{0.5,0.7,0.7\} & \{0.4,0.7,0.55\} \\
\{0.7,0.6,0.7\} & \{0.5,0.5,0.5\} & \{0.7,0.9,0.9\} & \{0.8,0.65,0.8\} \\
\{0.5,0.3,0.3\} & \{0.3,0.1,0.9\} & \{0.5,0.5,0.5\} & \{0.6,0.7,0.475\} \\
\{0.6,0.3,0.45\} & \{0.2,0.35,0.2\} & \{0.4,0.3,0.525\} & \{0.5,0.5,0.5\}
\end{array}\right] \\
& H^{* 2}=\left[\begin{array}{cccc}
\{0.5,0.5,0.5\} & \{0.3,0.5,0.55\} & \{0.1,0.2,0.45\} & \{0.6,0.4,0.6\} \\
\{0.7,0.5,0.45\} & \{0.5,0.5,0.5\} & \{0.7,0.8,0.45\} & \{0.1,0.3,0.5\} \\
\{0.9,0.8,0.55\} & \{0.3,0.2,0.55\} & \{0.5,0.5,0.5\} & \{0.5,0.6,0.7\} \\
\{0.4,0.6,0.4\} & \{0.9,0.7,0.5\} & \{0.5,0.4,0.3\} & \{0.5,0.5,0.5\}
\end{array}\right] \\
& H^{* 3}=\left[\begin{array}{cccc}
\{0.5,0.5,0.5\} & \{0.3,0.5,0.65\} & \{0.7,0.45,0.7\} & \{0.7,0.8,0.8\} \\
\{0.7,0.5,0.35\} & \{0.5,0.5,0.5\} & \{0.2,0.3,0.4\} & \{0.5,0.6,0.575\} \\
\{0.3,0.55,0.3\} & \{0.8,0.7,0.6\} & \{0.5,0.5,0.5\} & \{0.7,0.8,0.9\} \\
\{0.3,0.2,0.2\} & \{0.5,0.4,0.425\} & \{0.3,0.2,0.1\} & \{0.5,0.5,0.5\}
\end{array}\right] \\
& H^{* 4}=\left[\begin{array}{cccc}
\{0.5,0.5,0.5\} & \{0.4,0.5,0.6\} & \{0.3,0.4,0.4\} & \{0.5,0.7,0.7\} \\
\{0.6,0.5,0.4\} & \{0.5,0.5,0.5\} & \{0.3,0.425,0.3\} & \{0.6,0.7,0.8\} \\
\{0.7,0.6,0.6\} & \{0.7,0.575,0.7\} & \{0.5,0.5,0.5\} & \{0.8,0.9,0.625\} \\
\{0.5,0.3,0.3\} & \{0.4,0.3,0.2\} & \{0.2,0.1,0.375\} & \{0.5,0.5,0.5\}
\end{array}\right]
\end{aligned}
$$

\section{Consistency measures:}

Expressions (7)-(12) helped us to measure the consistency levels of the HFPRs provided by the decision makers as (26)-(29).

$$
\widetilde{H^{* 1}}=\left[\begin{array}{cccc}
\{0.5,0.5,0.5\} & \{0.3,0.4,0.3\} & \{0.5,0.7,0.7\} & \{0.4,0.7,0.55\} \\
\{0.7,0.6,0.7\} & \{0.5,0.5,0.5\} & \{0.7,0.9,0.9\} & \{0.8,0.65,0.8\} \\
\{0.5,0.3,0.3\} & \{0.3,0.1,0.9\} & \{0.5,0.5,0.5\} & \{0.6,0.7,0.475\} \\
\{0.6,0.3,0.45\} & \{0.2,0.35,0.2\} & \{0.4,0.3,0.525\} & \{0.5,0.5,0.5\}
\end{array}\right]
$$




$$
\begin{gathered}
\widetilde{H^{* 2}}=\left[\begin{array}{cccc}
\{0.5,0.5,0.5\} & \{0.4,0.45,0.55\} & \{0.15,0.25,0.45\} & \{0.5,0.4,0.6\} \\
\{0.6,0.55,0.45\} & \{0.5,0.5,0.5\} & \{0.65,0.75,0.45\} & \{0.2,0.35,0.5\} \\
\{0.85,0.75,0.55\} & \{0.35,0.25,0.55\} & \{0.5,0.5,0.5\} & \{0.45,0.55,0.7\} \\
\{0.4,0.6,0.4\} & \{0.8,0.65,0.5\} & \{0.55,0.45,0.3\} & \{0.5,0.5,0.5\}
\end{array}\right] \\
\widetilde{H^{* 3}}=\left[\begin{array}{cccc}
\{0.5,0.5,0.5\} & \{0.4,0.5,0.65\} & \{0.6,0.45,0.7\} & \{0.7,0.8,0.8\} \\
\{0.6,0.5,0.35\} & \{0.5,0.5,0.5\} & \{0.3,0.3,0.4\} & \{0.5,0.6,0.575\} \\
\{0.4,0.55,0.3\} & \{0.7,0.7,0.6\} & \{0.5,0.5,0.5\} & \{0.7,0.8,0.9\} \\
\{0.3,0.2,0.2\} & \{0.5,0.4,0.425\} & \{0.3,0.2,0.1\} & \{0.5,0.5,0.5\}
\end{array}\right] \\
\widetilde{H^{* 4}}=\left[\begin{array}{cccc}
\{0.5,0.5,0.5\} & \{0.4,0.5,0.6\} & \{0.3,0.4,0.4\} & \{0.5,0.7,0.7\} \\
\{0.6,0.5,0.4\} & \{0.5,0.5,0.5\} & \{0.3,0.425,0.3\} & \{0.6,0.7,0.8\} \\
\{0.7,0.6,0.6\} & \{0.7,0.575,0.7\} & \{0.5,0.5,0.5\} & \{0.8,0.9,0.625\} \\
\{0.5,0.3,0.3\} & \{0.4,0.3,0.2\} & \{0.2,0.1,0.375\} & \{0.5,0.5,0.5\}
\end{array}\right]
\end{gathered}
$$

(i). The consistency measures of pairs of alternatives in NHFPRs $H^{* q}, q=1,2,3,4$, are:

$$
\begin{gathered}
T_{L} C I\left(h_{i j}^{* 1}\right)=\left[\begin{array}{llll}
1 & 1 & 1 & 1 \\
1 & 1 & 1 & 1 \\
1 & 1 & 1 & 1 \\
1 & 1 & 1 & 1
\end{array}\right], T_{L} C I\left(h_{i j}^{* 2}\right)=\left[\begin{array}{cccc}
1 & 0.9500 & 0.9667 & 0.9667 \\
0.9500 & 1 & 0.9667 & 0.9500 \\
0.9667 & 0.9667 & 1 & 0.9667 \\
0.9667 & 0.9500 & 0.9667 & 1
\end{array}\right], \\
T_{L} C I\left(h_{i j}^{* 3}\right)=\left[\begin{array}{ccccc}
1 & 0.9667 & 0.9667 & 1 \\
0.9667 & 1 & 0.9667 & 1 \\
0.9667 & 0.9667 & 1 & 1 \\
1 & 1 & 1 & 1
\end{array}\right], T_{L} C I\left(h_{i j}^{* 4}\right)=\left[\begin{array}{cccc}
1 & 0.9500 & 0.9667 & 0.9667 \\
0.9500 & 1 & 0.9667 & 0.9500 \\
0.9667 & 0.9667 & 1 & 0.9667 \\
0.9667 & 0.9500 & 0.9667 & 1
\end{array}\right] .
\end{gathered}
$$

(ii). The consistency measures of alternatives $a_{1}, a_{2}, a_{3}$ and $a_{4}$ are:

$$
\begin{aligned}
& T_{L} C I\left(a_{1}\right)=(1,0.9611,0.9778,1), \quad T_{L} C I\left(a_{2}\right)=(1,0.9556,0.9778,1), \\
& T_{L} C I\left(a_{3}\right)=(1,0.9667,0.9778,1), \quad T_{L} C I\left(a_{4}\right)=(1,0.9611,1,1) .
\end{aligned}
$$

(iii). The consistency measures of NHFPRs are:

$$
\begin{aligned}
& T_{L} C I\left(H^{* 1}\right)=1, T_{L} C I\left(H^{* 2}\right)=0.961125, \\
& T_{L} C I\left(H^{* 3}\right)=0.98335, T_{L} C I\left(H^{* 4}\right)=1 .
\end{aligned}
$$

The global consistency index under the use of (11) is obtained as:

$$
C I=0.9861 .
$$

Now, the consistency weights of the decision makers $D_{1}, D_{2}, D_{3}$ and $D_{4}$ are estimated using (12) as:

$$
\begin{aligned}
& C w\left(D_{1}\right)=0.2535, C w\left(D_{2}\right)=0.2437, \\
& C w\left(D_{3}\right)=0.2493, C w\left(D_{4}\right)=0.2535 .
\end{aligned}
$$




\section{Consensus measures:}

(i). The consensus measures on each pair of alternatives are shown in the following, collectively aggregated, similarity matrix using (13):

$$
S=\left[\begin{array}{cccc}
1 & 0.9000 & 0.7500 & 0.8361 \\
0.9000 & 1 & 0.6486 & 0.7736 \\
0.7500 & 0.6486 & 1 & 0.8083 \\
0.8361 & 0.7736 & 0.8083 & 1
\end{array}\right]
$$

(ii). Based on similarity matrix $S$, the consensus measures on the alternatives $a_{1}, a_{2}, a_{3}$ and $a_{4}$, applying (14) are:

$$
\begin{aligned}
& C D_{1}=0.8287, C D_{2}=0.7708, \\
& C D_{3}=0.7356, C D_{4}=0.8060 .
\end{aligned}
$$

(iii). The consensus measure on the information provided by the decision makers is:

$$
C R=0.7853
$$

Final weights of decision makers:

The final weights of decision makers can be evaluated by using (19), but in this case the consistency weights $C w\left(D_{q}\right), q=1,2,3,4$, will be used as the final weights of the decision maker, because the predefined weights are not involved. Therefore, we have

$$
\begin{aligned}
& w\left(D_{1}\right)=0.2535, w\left(D_{2}\right)=0.2437 \\
& w\left(D_{3}\right)=0.2493, w\left(D_{4}\right)=0.2535
\end{aligned}
$$

Construction of collective NHFPR:

The collective NHFPR $H^{* c}$ is constructed after applying (20) and we get (30).

$$
H^{* \mathcal{C}}=\left[\begin{array}{cccc}
\{0.5,0.5,0.5\} & \{0.3746,0.4625,0.5242\} & \{0.3889,0.4520,0.5630\} & \{0.5245,0.6518,0.6625\} \\
\{0.6254,0.5375,0.4758\} & \{0.5,0.5,0.5\} & \{0.4867,0.5935,0.5136\} & \{0.5283,0.5771,0.6708\} \\
\{0.6111,0.5480,0.4370\} & \{0.5133,0.4065,0.4864\} & \{0.5,0.5,0.5\} & \{0.6391,0.7391,0.6738\} \\
\{0.4755,0.3482,0.3375\} & \{0.4717,0.4229,0.3292\} & \{0.3609,0.2609,0.3262\} & \{0.5,0.5,0.5\}
\end{array}\right]
$$

The final ranking of alternatives:

The expression (21) is used to get the final ranking order of the alternatives after evaluating the ranking values as: $v\left(a_{1}\right)=0.2558, v\left(a_{2}\right)=0.27825, v\left(a_{3}\right)=0.2808$ and $v\left(a_{4}\right)=0.18515$. Hence, the preference order of alternatives is

$$
a_{3} \succ a_{2} \succ a_{1} \succ a_{4}
$$

which leads us to the best alternative $a_{3}$, ecological factor, and suggests that the ecosystem must be protected primarily to ensure a healthy environment. While the economic factor is the second feasible choice, and the social factor carries third place in the ranking. The least important factor in the ranking order is the output and return.

The enhancement mechanism:

In order to incorporate the enhancement mechanism, we consider the threshold consensus level $\eta$ in the above example as 0.80 , while, the obtained value is $C R=0.7853$. Therefore, DMs have to change 
their preferences using (17), based on the mean values of the preferences provided by the expert shown as follows:

$$
H_{\text {ave }}=\left[\begin{array}{cccc}
\{0.5,0.5,0.5\} & \{0.325,0.475,0.525\} & \{0.4,0.4375,0.5625\} & \{0.55,0.65,0.6625\} \\
\{0.675,0.525,0.475\} & \{0.5,0.5,0.5\} & \{0.475,0.6062,0.5125\} & \{0.5,0.5625,0.6687\} \\
\{0.6,0.5625,0.4375\} & \{0.525,0.3938,0.4875\} & \{0.5,0.5,0.5\} & \{0.65,0.75,0.675\} \\
\{0.45,0.35,0.3375\} & \{0.5,0.4375,0.3312\} & \{0.35,0.25,0.325\} & \{0.5,0.5,0.5\}
\end{array}\right] .
$$

Now the identifier (17) provides the following set of positions to enhance the respective preference values

$$
I=\{(1,3),(2,3),(2,4),(3,1),(3,2),(4,2)\} .
$$

Suppose that the DMs welcomed the recommendations and improved their preference relations appropriately, given as

$$
\begin{gathered}
H_{\text {new }}^{1}=\left[\begin{array}{cccc}
\{0.5\} & \{0.3\} & \{0.45,0.5\} & \{0.4\} \\
\{0.7\} & \{0.5\} & \{0.48,0.62\} & \{0.5\} \\
\{0.55,0.5\} & \{0.52,0.38\} & \{0.5\} & \{0.6,0.7\} \\
\{0.6\} & \{0.5\} & \{0.4,0.3\} & \{0.5\}
\end{array}\right], \\
H_{\text {new }}^{2}=\left[\begin{array}{cccc}
\{0.5\} & \{0.3,0.5\} & \{0.38,0.41\} & \{0.6\} \\
\{0.7,0.5\} & \{0.5\} & \{0.48,0.63\} & \{0.45,0.55,0.65\} \\
\{0.62,0.59\} & \{0.52,0.37\} & \{0.5\} & \{0.5,0.6,0.7\} \\
\{0.4\} & \{0.55,0.45,0.35\} & \{0.5,0.4,0.3\} & \{0.5\}
\end{array}\right], \\
H_{\text {new }}^{3}=\left[\begin{array}{cccc}
\{0.5\} & \{0.3,0.5\} & \{0.45\} & \{0.7,0.8\} \\
\{0.7,0.5\} & \{0.5\} & \{0.38,0.58,0.5\} & \{0.5,0.57\} \\
\{0.55\} & \{0.62,0.42,0.5\} & \{0.5\} & \{0.7,0.8,0.9\} \\
\{0.3,0.2\} & \{0.5,0.43\} & \{0.3,0.2,0.1\} & \{0.5\}
\end{array}\right], \\
H_{\text {new }}^{4}=\left[\begin{array}{cccc}
\{0.5\} & \{0.4,0.5,0.6\} & \{0.38,0.55\} & \{0.5,0.7\} \\
\{0.6,0.5,0.4\} & \{0.5\} & \{0.45\} & \{0.55,0.57,0.68\} \\
\{0.62,0.45\} & \{0.55\} & \{0.5\} & \{0.8,0.9\} \\
\{0.5,0.3\} & \{0.45,0.43,0.32\} & \{0.2,0.1\} & \{0.5\}
\end{array}\right] .
\end{gathered}
$$

After normalizing these HFPRs using (1)-(6), and constructing consistent HFPRs using (7), the consistency indices of new NHFPRs can be evaluated as:

$$
\begin{aligned}
& T_{L} C I\left(H_{\text {new }}^{* 1}\right)=1, T_{L} C I\left(H_{\text {new }}^{* 2}\right)=1, \\
& T_{L} C I\left(H_{\text {new }}^{* 3}\right)=1, T_{L} C I\left(H_{\text {new }}^{* 4}\right)=1 .
\end{aligned}
$$

We developed the collective similarity matrix $S_{\text {new }}$ with (13), and is given as follows:

$$
S_{\text {new }}=\left[\begin{array}{llll}
1.0000 & 0.9233 & 0.9406 & 0.8433 \\
0.9233 & 1.0000 & 0.9374 & 0.9456 \\
0.9406 & 0.9374 & 1.0000 & 0.8151 \\
0.8433 & 0.9456 & 0.8151 & 1.0000
\end{array}\right] .
$$


The consensus measures on the alternatives $a_{1}, a_{2}, a_{3}$ and $a_{4}$ are estimated after applying (14) on similarity matrix $S_{\text {new }}$ as:

$$
\begin{aligned}
& C D_{1 \text { new }}=0.9024, C D_{2 \text { new }}=0.9354, \\
& C D_{3 \text { new }}=0.8977, C D_{4 \text { new }}=0.8680 .
\end{aligned}
$$

Hence, the consensus measure on the information provided by the decision makers is evaluated by (16):

$$
C R_{\text {пет }}=0.9009 .
$$

This shows that the enhancement mechanism clearly improves the consensus level amongst DMs from $C R=0.7853$ to $C R_{\text {new }}=0.9009$ which is higher than the threshold level $\eta=0.80$ i.e., $C R_{\text {new }}>\eta$. Now, the collective NHFPR $H_{\text {new }}^{* c}$ can be constructed using (19) and (20), given as below: The expression (21) is used to get the final ranking order of the alternatives after evaluating the ranking values as: $v\left(a_{1}\right)=0.2473, v\left(a_{2}\right)=0.2719, v\left(a_{3}\right)=0.2876$ and $v\left(a_{4}\right)=0.1932$. Therefore, the preference order of alternatives is $a_{3} \succ a_{2} \succ a_{1} \succ a_{4}$, and is same as before the application of enhancement mechanism.

$$
H_{\text {new }}^{* c}=\left[\begin{array}{lllll}
\{0.5000,0.5000,0.5000\} & \{0.3250,0.4850,0.4625\} & \{0.4150,0.4950,0.4875\} & \{0.5500,0.6538,0.5787\} \\
\{0.6750,0.5150,0.5375\} & \{0.5000,0.5000,0.5000\} & \{0.4475,0.5650,0.4794\} & \{0.5000,0.5675,0.6075\} \\
\{0.5850,0.5050,0.5125\} & \{0.5525,0.4350,0.5206\} & \{0.5000,0.5000,0.5000\} & \{0.6500,0.7500,0.6656\} \\
\{0.4500,0.3463,0.4213\} & \{0.5000,0.4325,0.3925\} & \{0.3500,0.2500,0.3344\} & \{0.5000,0.5000,0.5000\}
\end{array}\right]
$$

\section{Comparison}

To clearly validate the proposed procedure, we compare our results to findings of $\mathrm{Xu}$ et al. [31] based on consistency measure, consensus measure and the final ranking. The initial consistency levels, consensus level and the final ranking of alternatives in $\mathrm{Xu}$ et al. [31]'s sense based on additive transitivity are: $c l^{1}=0.9750, c l^{2}=0.8833, c l^{3}=0.9389, c l^{4}=0.9847 ; C R=0.7653$ and $a_{3} \succ a_{2} \succ a_{1} \succ a_{4}$, respectively.

In our proposed scheme, $T_{L}$-transitivity is introduced to evaluate the unknown elements of HFPVs in the normalization process and construct the consistent HFPRs, accordingly. Consequently, the initial consistency indices, consensus level amongst DMs and final ranking order of alternatives are: $T_{L} C I\left(H^{* 1}\right)=1, T_{L} C I\left(H^{* 2}\right)=0.961125, T_{L} C I\left(H^{* 3}\right)=0.98335, T_{L} C I\left(H^{* 4}\right)=1 ; C R=0.7853$ and $a_{3} \succ a_{2} \succ a_{1} \succ a_{4}$, respectively. Evidently, the consistency and consensus levels estimated by the proposed method are higher than the levels obtained by Xu et al. [31]'s procedure, but the final ranking order of both the methods are identical. This shows that $T_{L}$-transitive property is much useful to strengthen the consistency of data, and consensus amongst DMs, as well. To incorporate the enhancement mechanism to improve the consensus level amongst DMs, we considered the case with threshold consensus level $\eta=0.80$ and estimated the new global consensus level. After applying simple steps of enhancement mechanism, we evaluated the global consensus level $C R_{\text {new }}=0.9009$ which shows a significant improvement when comparing to the threshold level. Most interestingly, we obtained the same ranking order $a_{3} \succ a_{2} \succ a_{1} \succ a_{4}$ of alternatives before the application of the enhancement mechanism. Thus, it validates and strengthens the proposed scheme. In an easy manner, the following Table 1 provides the information to observe and compare the values obtained in [31] and proposed schemes: 
Table 1. Comparison of reference results and the proposed approach.

\begin{tabular}{lccccccc}
\hline \multirow{2}{*}{ Methods } & \multicolumn{4}{c}{ Consistency Levels of } & Consensus Level & Ranking \\
\cline { 2 - 5 } & $\boldsymbol{H}^{\mathbf{1}}$ & $\boldsymbol{H}^{\mathbf{2}}$ & $\boldsymbol{H}^{\mathbf{3}}$ & $\boldsymbol{H}^{\mathbf{4}}$ & $(\boldsymbol{C R})$ & Order \\
\hline Xu et al. [31] & 0.9750 & 0.8833 & 0.9389 & 0.9847 & 0.7653 & $a_{3} \succ a_{2} \succ a_{1} \succ a_{4}$ \\
\hline Proposed (Round 1) & 1 & 0.9611 & 0.9834 & 1 & 0.7853 & $a_{3} \succ a_{2} \succ a_{1} \succ a_{4}$ \\
\hline Proposed (Round 2) & 1 & 1 & 1 & 1 & 0.9009 & $a_{3} \succ a_{2} \succ a_{1} \succ a_{4}$ \\
\hline
\end{tabular}

Here, Rounds 1 and 2 represent the evaluations before and after application of the enhancement mechanism, respectively.

\section{Conclusions}

In this manuscript, a consensus-based method to handle the MPDM problem using consistent HFPRs is proposed. In this regard, the definition of HFPRs has been borrowed from Xu et al. [31]'s work, and an efficient $T_{L}$-consistency-based procedure to normalize HFPRs is presented. A step by step procedure to normalize the HFPR is shown in Example 1. The consistency weights have been assigned to DMs after the consistency analysis made, it is rational to allocate higher weights to DMs with a high level of consistency in order to carry more importance in the aggregation process. Furthermore, an enhancement mechanism is incorporated to accelerate the execution of a higher consensus level on an easy path. After reaching an acceptable consensus level amongst DMs, the entire process moves to the selection phase, comprising of aggregation and ranking processes, to select the best alternative. A comparative example is elaborated to highlight the practicality with the efficiency of the proposed method. The results help us to have greater insight into the MPDM process.

A few of the main advantages of the setting method are: (1) In this article, Łukasiewicz transitivity is used to determine the unspecified preference values in order to normalize the HFPRs. Compared to some other approaches focused on consistency measures, Łukasiewicz transitivity generates better values and consistency as well. (2) The priority weights are assigned to DMs after merging the consistency weights, based on the information provided, and the predefined weights (if any) that play a significant role in assessing the consistency indices of the DM opinions. (3) The enhancement mechanism helps DMs to think in various directions in order to reach a consensus among them. We believe that there are only a few techniques of this kind presented in the literature to deal with MPDM in HFPRs' setting. (4) There is no need to simulate proximity measures in the proposed method, which decreases the computing workload while accelerating the speed at which consensus is achieved. (5) The proposed method resulted in highly consistent NHFPRs as compare to the model given in [31]. (6) In the end, consistent NHFPRs are aggregated into collective consistent NHFPR in order to achieve the ranking order of alternatives. Because it is quite often that the preference values provided by DMs are weighted differently, if the $\mathrm{DMs}^{\prime}$ weights have been calculated, their views are to be aggregated into a global one.

At the same time, there are certain limitations to be discussed in future study: (1) The GDM could contain too many parameters in the decision-making process, including cognitive science, political culture, people's risk attitudes, etc., that certain variables need to be taken into account. (2) When voicing their preferential relationships, experts can show some degree of reluctance. Thus in the case of type-2 fuzzy preference relations, it would be interesting to establish processes to deal with GDM. (3) The threshold consensus measure directly affects the consensus round but is normally decided in advance. How this criterion will be calculated on the basis of multiple parameters, e.g., the number of experts, the number of requirements, or alternatives, may be fascinating to see.

The traditional approach of consensus building fails to consider more uncertain factors and limitations of the language scale. Therefore, it would be interesting to propose another approach for consensus building in group decision making based on $T_{L}$-consistency in clustering analysis 
and medical diagnosis in the framework of various linguistic settings like hesitant fuzzy linguistic preference relation, hesitant intuitionistic fuzzy linguistic preference relation, etc. as future research. The consensus-reaching process for complex linguistic information [49] is another interesting research area for a future study.

Author Contributions: Conceptualization, A.-u.R., J.W., S.F., T.R., and M.T.-Ł.; methodology, A.-u.R., J.W., S.F., T.R., and M.T.-Ł.; software, A.-u.R., J.W., S.F., T.R., and M.T.-Ł.; validation, A.-u.R., J.W., S.F., T.R., and M.T.-Ł.; formal analysis, A.-u.R., J.W., S.F., T.R., and M.T.-Ł.; investigation, A.-u.R., J.W., S.F., T.R., and M.T.-Ł.; resources, A.-u.R., J.W., S.F., T.R., and M.T.-Ł.; data curation, A.-u.R., J.W., S.F., T.R., and M.T.-Ł.; writing-original draft preparation, A.-u.R., J.W., S.F., T.R., and M.T.-Ł.; writing-review and editing, A.-u.R., J.W., S.F., T.R., and M.T.-Ł.; visualization, A.-u.R., J.W., S.F., T.R., and M.T.-Ł.; supervision, A.-u.R., J.W., S.F., T.R., and M.T.-Ł.; project administration, S.F., J.W.; funding acquisition, J.W. and M.T.-Ł. All authors have read and agreed to the published version of the manuscript.

Funding: The work was supported by the project financed within the framework of the program of the Minister of Science and Higher Education under the name "Regional Excellence Initiative" in the years 2019-2022, Project Number 001/RID/2018/19; the amount of financing: PLN 10.684.000,00 (J.W.; M.T.-Ł.-Ł.).

Acknowledgments: The authors would like to thank the editor and the anonymous reviewers, whose insightful comments and constructive suggestions helped us to significantly improve the quality of this paper.

Conflicts of Interest: The authors declare no conflict of interest.

\section{References}

1. Watróbski, J.; Jankowski, J.; Ziemba, P.; Karczmarczyk, A.; Zioło, M. Generalised framework for multi-criteria method selection. Omega 2019, 86, 107-124. [CrossRef]

2. Shekhovtsov, A.; Kołodziejczyk, J.; Sałabun, W. Fuzzy Model Identification Using Monolithic and Structured Approaches in Decision Problems with Partially Incomplete Data. Symmetry 2020, 12, 1541. [CrossRef]

3. Stojčić, M.; Zavadskas, E.K.; Pamučar, D.; Stević, Ž.; Mardani, A. Application of MCDM methods in sustainability engineering: A literature review 2008-2018. Symmetry 2019, 11, 350. [CrossRef]

4. Shekhovtsov, A.; Kozlov, V.; Nosov, V.; Sałabun, W. Efficiency of Methods for Determining the Relevance of Criteria in Sustainable Transport Problems: A Comparative Case Study. Sustainability 2020, 12, 7915. [CrossRef]

5. Chatterjee, K.; Pamucar, D.; Zavadskas, E.K. Evaluating the performance of suppliers based on using the R'AMATEL-MAIRCA method for green supply chain implementation in electronics industry. J. Clean. Prod. 2018, 184, 101-129. [CrossRef]

6. Pamučar, D.; Mihajlović, M.; Obradović, R.; Atanasković, P. Novel approach to group multi-criteria decision making based on interval rough numbers: Hybrid DEMATEL-ANP-MAIRCA model. Expert Syst. Appl. 2017, 88, 58-80. [CrossRef]

7. Sałabun, W.; Wattróbski, J.; Shekhovtsov, A. Are MCDA Methods Benchmarkable? A Comparative Study of TOPSIS, VIKOR, COPRAS, and PROMETHEE II Methods. Symmetry 2020, 12, 1549. [CrossRef]

8. Dong, Y.; Zhang, H. Multiperson decision making with different preference representation structures: A direct consensus framework and its properties. Knowl. Based Syst. 2014, 58, 45-57. [CrossRef]

9. Xu, Y.; Wen, X.; Zhang, W. A two-stage consensus method for large-scale multi-attribute group decision making with an application to earthquake shelter selection. Comput. Ind. Eng. 2018, 116, 113-129. [CrossRef]

10. Pamučar, D.; Petrović, I.; Ćirović, G. Modification of the Best-Worst and MABAC methods: A novel approach based on interval-valued fuzzy-rough numbers. Expert Syst. Appl. 2018, 91, 89-106. [CrossRef]

11. Wu, J.; Dai, L.; Chiclana, F.; Fujita, H.; Herrera-Viedma, E. A minimum adjustment cost feedback mechanism based consensus model for group decision making under social network with distributed linguistic trust. Inf. Fusion 2018, 41, 232-242. [CrossRef]

12. Zhang, C.; Zhang, H.; Wang, J. Personalized restaurant recommendation method combining group correlations and customer preferences. Inf. Sci. 2018, 454, 128-143. [CrossRef]

13. Li, Y.; Zhang, H.; Dong, Y. The interactive consensus reaching process with the minimum and uncertain cost in group decision making. Appl. Soft Comput. 2017, 60, 202-212. [CrossRef]

14. Li, J.; Wang, Z.X. Consensus building for probabilistic hesitant fuzzy preference relations with expected additive consistency. Int. J. Fuzzy Syst. 2018, 20, 1495-1510. [CrossRef] 
15. Tian, Z.P.; Wang, J.Q.; Zhang, H.Y.; Wang, T.L. Signed distance-based consensus in multi-criteria group decision-making with multi-granular hesitant unbalanced linguistic information. Comput. Ind. Eng. 2018, 124, 125-138. [CrossRef]

16. Zhang, H.; Dong, Y.; Herrera-Viedma, E. Consensus building for the heterogeneous large-scale GDM with the individual concerns and satisfactions. IEEE Trans. Fuzzy Syst. 2017, 26, 884-898. [CrossRef]

17. Herrera-Viedma, E.; Cabrerizo, F.J.; Kacprzyk, J.; Pedrycz, W. A review of soft consensus models in a fuzzy environment. Inf. Fusion 2014, 17, 4-13. [CrossRef]

18. Xia, M.; Xu, Z. Managing hesitant information in GDM problems under fuzzy and multiplicative preference relations. Int. J. Uncertainty Fuzziness Knowl. Based Syst. 2013, 21, 865-897. [CrossRef]

19. He, Y.; Xu, Z. A consensus reaching model for hesitant information with different preference structures. Knowl. Based Syst. 2017, 135, 99-112. [CrossRef]

20. Wu, Z.; Jin, B.; Xu, J. Local feedback strategy for consensus building with probability-hesitant fuzzy preference relations. Appl. Soft Comput. 2018, 67, 691-705. [CrossRef]

21. Xu, Y.; Chen, L.; Rodríguez, R.M.; Herrera, F.; Wang, H. Deriving the priority weights from incomplete hesitant fuzzy preference relations in group decision making. Knowl. Based Syst. 2016, 99, 71-78. [CrossRef]

22. Meng, F.; An, Q. A new approach for group decision making method with hesitant fuzzy preference relations. Knowl. Based Syst. 2017, 127, 1-15. [CrossRef]

23. Zhu, B.; Xu, Z.; Xu, J. Deriving a ranking from hesitant fuzzy preference relations under group decision making. IEEE Trans. Cybern. 2013, 44, 1328-1337. [CrossRef] [PubMed]

24. Faizi, S.; Sałabun, W.; Rashid, T.; Wątróbski, J.; Zafar, S. Group decision-making for hesitant fuzzy sets based on characteristic objects method. Symmetry 2017, 9, 136. [CrossRef]

25. Ali, A.; Rashid, T. Hesitant fuzzy best-worst multi-criteria decision-making method and its applications. Int. J. Intell. Syst. 2019, 34, 1953-1967. [CrossRef]

26. Zhang, Z.; Wu, C. A decision support model for group decision making with hesitant multiplicative preference relations. Inf. Sci. 2014, 282, 136-166. [CrossRef]

27. Meng, F.; Tang, J.; An, Q.; Chen, X. A new procedure for hesitant multiplicative preference relations. Int. J. Intell. Syst. 2019, 34, 819-857. [CrossRef]

28. Zhang, Z. Deriving the priority weights from incomplete hesitant fuzzy preference relations based on multiplicative consistency. Appl. Soft Comput. 2016, 46, 37-59. [CrossRef]

29. Li, H.; Yin, S.; Yang, Y. Some preference relations based on q-rung orthopair fuzzy sets. Int. J. Intell. Syst. 2019, 34, 2920-2936. [CrossRef]

30. Zhang, C.; Liao, H.; Luo, L. Additive consistency-based priority-generating method of q-rung orthopair fuzzy preference relation. Int. J. Intell. Syst. 2019, 34, 2151-2176. [CrossRef]

31. Xu, Y.; Cabrerizo, F.J.; Herrera-Viedma, E. A consensus model for hesitant fuzzy preference relations and its application in water allocation management. Appl. Soft Comput. 2017, 58, 265-284. [CrossRef]

32. Ureña, R.; Chiclana, F.; Morente-Molinera, J.A.; Herrera-Viedma, E. Managing incomplete preference relations in decision making: a review and future trends. Inf. Sci. 2015, 302, 14-32. [CrossRef]

33. Zhang, Z.; Guo, C. An approach to group decision making with heterogeneous incomplete uncertain preference relations. Comput. Ind. Eng. 2014, 71, 27-36. [CrossRef]

34. Zhang, Z.; Wang, C.; Tian, X. Multi-criteria group decision making with incomplete hesitant fuzzy preference relations. Appl. Soft Comput. 2015, 36, 1-23. [CrossRef]

35. Khalid, A.; Beg, I. Incomplete hesitant fuzzy preference relations in group decision making. Int. J. Fuzzy Syst. 2017, 19, 637-645. [CrossRef]

36. Wind, Y.; Saaty, T.L. Marketing applications of the analytic hierarchy process. Manag. Sci. 1980, 26, 641-658. [CrossRef]

37. Zhu, B. Studies on consistency measure of hesitant fuzzy preference relations. Procedia Comput. Sci. 2013, 17, 457-464. [CrossRef]

38. Zhang, Z. A framework of group decision making with hesitant fuzzy preference relations based on multiplicative consistency. Int. J. Fuzzy Syst. 2017, 19, 982-996. [CrossRef]

39. Kizielewicz, B.; Sałabun, W. A New Approach to Identifying a Multi-Criteria Decision Model Based on Stochastic Optimization Techniques. Symmetry 2020, 12, 1551. [CrossRef] 
40. Liu, X.; Xu, Y.; Montes, R.; Dong, Y.; Herrera, F. Analysis of self-confidence indices-based additive consistency for fuzzy preference relations with self-confidence and its application in group decision making. Int. J. Intell. Syst. 2019, 34, 920-946. [CrossRef]

41. Tanino, T. Fuzzy preference relations in group decision making. In Non-Conventional Preference Relations in Decision Making; Springer: Berlin/Heidelberg, Germany, 1988; pp. 54-71.

42. Venugopalan, P. Fuzzy ordered sets. Fuzzy Sets Syst. 1992, 46, 221-226. [CrossRef]

43. Zadeh, L.A. Fuzzy sets. Inf. Control. 1965, 8, 338-353. [CrossRef]

44. Torra, V. Hesitant fuzzy sets. Int. J. Intell. Syst. 2010, 25, 529-539. [CrossRef]

45. Xia, M.; Xu, Z. Hesitant fuzzy information aggregation in decision making. Int. J. Approx. Reason. 2011, 52, 395-407. [CrossRef]

46. Tanino, T. Fuzzy preference orderings in group decision making. Fuzzy Sets Syst. 1984, 12, 117-131. [CrossRef]

47. Herrera-Viedma, E.; Chiclana, F.; Herrera, F.; Alonso, S. Group decision-making model with incomplete fuzzy preference relations based on additive consistency. IEEE Trans. Syst. Man Cybern. Part B (Cybern.) 2007, 37, 176-189. [CrossRef] [PubMed]

48. Xu, Z.; Xia, M. Distance and similarity measures for hesitant fuzzy sets. Inf. Sci. 2011, 181, $2128-2138$. [CrossRef]

49. Wu, X.L.; Liao, H.C. A consensus-based probabilistic linguistic gained and lost dominance score method. Eur. J. Oper. Res. 2019, 272, 1017-1027. [CrossRef]

Publisher's Note: MDPI stays neutral with regard to jurisdictional claims in published maps and institutional affiliations.

(C) 2020 by the authors. Licensee MDPI, Basel, Switzerland. This article is an open access article distributed under the terms and conditions of the Creative Commons Attribution (CC BY) license (http:/ / creativecommons.org/licenses/by/4.0/). 